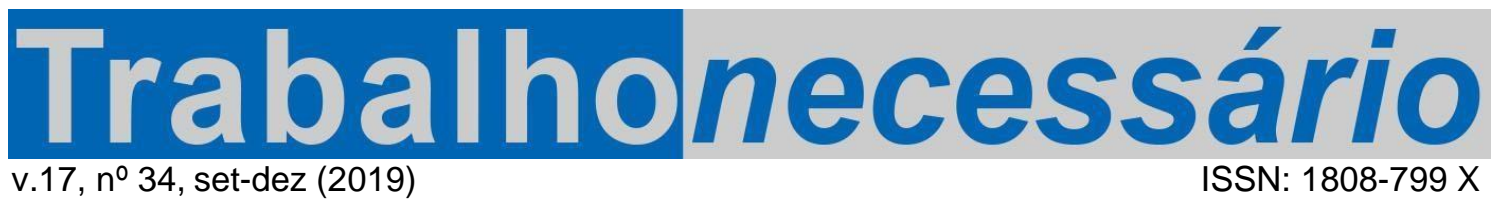

\title{
PAUL SINGER E A PEDAGOGIA DA AUTOGESTÃO NA ECONOMIA SOLIDÁRIA ${ }^{1}$
}

\author{
Cláudio Nascimento ${ }^{2}$ \\ Resumo \\ Aline Mendonça dos Santos ${ }^{3}$
}

A economia solidária como estratégia político-pedagógica em prol da democracia e de outro projeto societário esteve presente na agenda do movimento de economia solidária. Não por acaso, sempre foi compreendida como uma perspectiva real de transformação da realidade social por aquele que foi a maior referência de economia solidária no Brasil: Paul Singer. Este artigo propõe traçar os esforços teóricos, políticos e práticos que Paul Singer desenvolveu ao longo de sua trajetória pessoal e profissional para contribuir no avanço da autogestão e da economia solidária, entendida como ato pedagógico e como estratégia de desenvolvimento.

Palavras-chave: Paul Singer; Economia Solidária; Autogestão; Democracia; Pedagogia.

\section{PAUL SINGER: ALGUNAS HIPÓTESIS SOBRE LA PEDAGOGÍA DE LA AUTOGESTIÓN}

\section{Resumen}

La economía solidaria como estrategia político pedagógica hacia la democracia y de un otro proyecto societario siempre estuvo presente en la agenda del movimiento de economía solidaria. No por casualidad, la economía solidaria siempre fue comprendida como una perspectiva real de transformación de la realidad social por aquel que fue la mayor referencia de la economía solidaria en Brasil: Paul Singer. Este artículo propone trazar los esfuerzos teóricos, políticos y prácticos que Paul Singer desarrolló al largo de su trayectoria personal y profesional para avanzar la autogestión y la economía solidaria como acto pedagógico y como estrategia de desarrollo.

Palabras clave: Paul Singer; Economía Solidaria; Autogestión; Democracia; Pedagogía.

\section{PAUL SINGER: SOME HYPOTHESIS ON SELF-MANAGEMENT PEDAGOGY}

\begin{abstract}
Solidarity popular economy as a political-pedagogical strategy in favor of a democracy concerning a societary project has always been on the agenda of its movement. Not coincidentally, solidarity economy has always been considered as a concrete perspective for transforming the social reality by the one who is considered the biggest reference in solidarity economy in Brazil: Paul Singer. This article has the objective of outlining the practical, theoretical and political efforts that Paul Singer has developed throughout his personal and professional trajectory, in order to promote self-management and solidarity economy as a pedagogical act and as a development strategy.
\end{abstract}

Keywords: Paul Singer, Solidarity Economy, Self-Management, Democracy, Pedagogy

${ }^{1}$ Recebido em 01/06/2019. Primeira avaliação: 15/06/2019. Segunda avaliação: 17/07/2019.

Aprovado em 02/08/2019. Publicado em 27/09/2019.

DOI: https://doi.org/10.22409/tn.17i34.p38048.

${ }^{2}$ Educador popular. Coordenador geral de educação na Secretaria Nacional de Economia Solidária SENAES, entre 2003 e 2007. Autor de ensaios e livros sobre autogestão e educação popular, como "O Movimento pela Autogestão na Polônia", "Rosa Luxemburgo e Solidarnosc", "Autogestão e economia solidaria", "O beco dos sapos" e "Pedagogia da Autogestão". E-mail: claudan@terra.com.br ${ }^{3}$ Doutora pela Universidade do Estado do Rio de Janeiro (2010), com pós-doutorado na Universidade de Coimbra (CES - UC). Pesquisadora do CES - Universidade de Coimbra. Coordenadora do Programa de Pós-Graduação em Política Social e Direitos Humanos da Universidade Católica de Pelotas. E-mail: ppgps@ucpel.edu.br. https://orcid.org/0000-0002-1902-0293 


\section{Introdução}

Nas últimas décadas temos presenciado a legitimidade do processo da economia solidária (ECOSOL) no Brasil. Tal dinamização se deu através da ação política da economia popular solidária desdobrada em ações do movimento social e ação do Estado. Apesar destas duas frentes de atuação, tratou-se de um processo muito articulado, uma vez que a criação do Fórum Brasileiro da Economia Solidária (FBES), a elaboração de uma Carta de Princípios e de uma Plataforma da Economia Solidária $^{3}$ se concretizou na terceira Plenária Nacional da Economia Solidária (PNES) em junho de 2003, mesma época de implantação oficial da Secretaria Nacional de Economia Solidária (SENAES) no Ministério do Trabalho e Emprego (MTE). Desta forma, instâncias da economia solidária no plano nacional, tanto da sociedade como do Estado, se deram num mesmo momento histórico através de processos interligados (CUNHA \& SANTOS, 2010).

Desde a criação dessas instâncias políticas, presenciou-se uma relação bastante estreita entre Estado e sociedade para a gestão da política de economia solidária. Foram muitos os questionamentos sobre o papel do FBES frente ao Estado ou quanto à sua composição e estrutura de gestão (objetos de grande disputa quando da quarta Plenária Nacional em 2008), mas é difícil negar que, na ocasião, tenha obtido a posição de principal rede nacional da economia solidária no Brasil. Mais tarde, buscou-se institucionalizar espaços de diálogo entre Estado e sociedade, como a Conferência Nacional e o Conselho Nacional. São espaços que apontam para possíveis conteúdos e formatos diferenciados na relação com a sociedade, sobretudo no que se refere às características históricas do Estado brasileiro, mas ainda apresentam muitos limites para a participação e o controle social na definição de ações e alocação de recursos públicos.

Dentre as questões que estiveram na agenda de diálogo entre Estado (SENAES) e sociedade (FBES) para a elaboração da política de economia solidária está a questão da educação (formação e assessoria técnica) para a economia solidária. Assim, a educação está entre as bandeiras de luta do movimento da economia solidária deste a criação da primeira plataforma de luta criada pelo FBES.

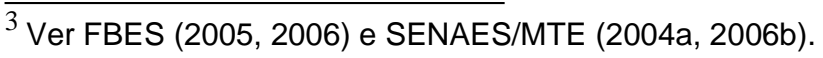


Em estudo anterior (Adams \& Santos, 2013) fez-se uma revisão histórica da importância desta temática para o movimento.

No contexto do Estado, mais especificamente na SENAES, tivemos sujeitos políticos, companheiros de movimento, comprometidos com a educação como estratégia para a economia solidária. Mas, dentre esses, destacamos a importância de Paul Singer, aquele que esteve à frente da SENAES de 2003 a 2016 e que sempre acreditou na economia solidária como um ato pedagógico.

A proposta deste artigo é, justamente, refletir sobre a importância e a influência de Paul Singer na construção dos processos educativos da economia solidária ou economia solidária que, mais adiante, se constituíram no que chamamos de pedagogia da autogestão, compreendendo que:

a partir da prática autogestionária potencializada pela economia solidária, os trabalhadores compõem uma condição de sujeito econômico, social e político que considera a reprodução social da vida frente às regras das relações capitalistas de produção. Percebese aí um processo pedagógico que produz novas representações de mundo que precisa ser compreendido e reconhecido, tendo em vista o potencial emancipatório do trabalho associado e autogestionário. Diante desta premissa, o movimento de economia solidária no Brasil, estimulado pelo Fórum Brasileiro de Economia Solidária (FBES), vem provocando uma série de questionamentos em torno das dimensões educativas do trabalho associado compreendendo a necessidade de articular os saberes que a organização capitalista do trabalho fragmentou. Para tanto, há um exercício de reconhecer e estimular uma pedagogia da autogestão - que significa o processo pedagógico no âmbito do trabalho associado e autogestionário - e reconhecer e estimular uma autogestão da pedagogia - que significa ter a experiência da autogestão como referência de processos pedagógicos e formativos sobre economia solidária que possuem a educação popular como base. (ADAMS \& SANTOS, 2013, p 260261).

É importante destacar que a discussão desenvolvida neste texto é resultado de um trabalho de pesquisa militante, ou seja, de pesquisadores que participam e partilham do projeto social e político de seus campos de estudo (Cunha \& Santos, 2010) - uma vez que os autores deste trabalho se reconhecem como sujeitos políticos do movimento da economia solidária, participaram da gestão de políticas públicas da SENAES, fizeram parte dos processos de constituição dos Centros de Formação em Economia Solidária (CFES) do país, onde, como educadores, uniram esforços para legitimar um processo metodológico que visava autogestão da pedagogia e a pedagogia da autogestão e, além disso, ambos tiveram espaços de diálogo e partilha muito próximos do professor Paul Singer e sua obra. 
À luz desta concepção, trabalhamos este texto dividido em cinco momentos: primeiramente apontamos algumas considerações sobre a importância da educação para o movimento da economia solidária; logo fazemos uma reflexão sobre as experiências de Paul Singer frente uma dinâmica pedagógica de produção da democracia; na sequência construímos uma linha de reflexão de Singer sobre a construção da autogestão como estratégia política; no quarto momento traçamos os esforços de constituir um processo de educação em economia solidária por dentro da política da SENAES; e, por fim, pontuamos algumas reflexões finais sobre a perspectiva de Singer na compreensão da economia solidária como atopedagógico.

\section{Considerações sobre educação e economia solidária}

Após alguns anos acompanhando o processo de formação de formadores com os educadores dos Centros de Formação em Economia Solidária (CFES), fizemos algumas sistematizações sobre o que chamamos de 'pedagogia da autogestão / autogestão da pedagogia': um processo duplo de autogestão do ato educativo em si, enquanto construção coletiva do conhecimento, e também da dinâmica desse processo ${ }^{4}$.

No presente artigo, buscamos centrar o tema em torno das ideias de Paul Singer, apenas citado como inspiração nos trabalhos anteriores. Esta proposta de refletir uma pedagogia da autogestão a partir obra de Singer, ocorreu a partir de 2018, quando em decorrência da morte do professor Singer, resolvemos homenageá-lo em um livro intitulado "Paul Singer. Economia, Democracia, Autogestão" (Santos; Nascimento, 2018), onde nos dedicamos a expor sua trajetória de vida e luta pela democracia, bem como analisar a construção da visão de mundo de Singer sobre socialismo/autogestão. No esforço de elaboração deste livro, já no início, ao analisarmos a primeira parte da trajetória de Singer, nos defrontamos com elementos fundamentais para a construção de sua ação educativa.

\footnotetext{
${ }^{4} \mathrm{O}$ ensaio intitulado "Experimentação autogestionária: pedagogia da autogestão e autogestão da pedagógica" foi publicado em 2011 e 2013. A primeira vez, pelo "Intercâmbio, Informações, Estudos e Pesquisas" (IIEP), em uma Coletânea de ensaios (NASCIMENTO, 2011). A segunda publicação, na obra coletiva "Trabalho, Educação e Reprodução Social" organizado por Eraldo Batista e Henrique Novaes. Neste ensaio, as principais fontes foram europeias: Jef Ulburghs da Bélgica, Daniel Mothé, Pierre Naville, G. Canguilhem e Yves Schwartz da França, Kardejl da Yugoslavia, Raymond Williams e Edward Thompson da Inglaterra, mas sempre com aportes de Antônio Gramsci e Paulo Freire.
} 
A construção de uma pedagogia da autogestão buscava sistematizar o processo educativo de construção da política pública de educação da economia solidaria na SENAES, a articulação do Estado com os movimentos sociais na construção a economia solidária como ato pedagógico, a experiência concreta dos empreendimentos econômicos solidários no processo de reconhecer seu processo de trabalho e de envolvimento com o movimento como processos educativos.

O conjunto destas sistematizações foi refletido no texto "Economia Solidaria: um espaço peculiar de educação popular" (Adams \& Santos, 2013). A primeira referência de esforços de um projeto de educação no âmbito da economia solidária foi a realização, em 2005 e 2007, de duas oficinas metodológicas nacionais, agrupando as entidades, empreendimentos econômicos solidários e movimentos que desenvolviam práticas educativas neste campo, na busca da construção dos elementos dessa política. A partir destas oficinas, passamos a refletir a estrutura educativa para economia solidaria, que resultou na ideia da rede CFES, como segundo passo estratégico ${ }^{5}$.

Este processo foi sendo finalizado com a Oficina Temática "Educação e Autogestão", em 2016, no final do governo Dilma, obstruído pelo processo de impeachment da presidente. O Golpe de Estado que o Brasil sofreu naquele ano resultou em mudanças qualitativas na SENAES, sobretudo, pela saída de Paul Singer como secretário. A partir desse momento, a economia solidaria iniciou um processo de resistência política e, no campo educativo, foi o final da Rede CFES e de conjunto significativo de projetos e programas da política de economia solidária no Brasil. Desde então, a política pública da SENAES se resumiu a um Projeto, o de Construção de Redes Solidarias, tendo à sua frente a Agência de Desenvolvimento

\footnotetext{
${ }^{5}$ O CFES nacional ainda teve condições de articular seus quatro núcleos temáticos nacionais e publicar o Caderno Referencias Metodológicos de Formação e Assessoria Técnica em economia Solidaria" organizado pela Cáritas Nacional e que teve "A educação em economia Solidaria" de Telmo Adams e José Ignácio Neutzling como primeiro capítulo. Nessa mesma perspectiva, Henrique Novaes e Mariana Castro, apresentaram um ensaio, em 2011 intitulado "Em busca de uma pedagogia da produção associada"; e, posteriormente, Novaes (2018) fez uma primeira tentativa tendo o CFES como objeto de análise "Os CFES: as contradições da educação autogestionária do movimento da economia solidaria". No início da SENAES, foi muito importante a obra coletiva organizada por Lia Tiriba e Iracy Picanço, "Trabalho e educação, Arquitetos, abelhas e outros tecelões da economia popular e solidaria" (2004) e, por fim, o ensaio de Lia Tiriba e Maria Clara Bueno Fischer, "Saberes do Trabalho Associado", no Dicionário Internacional da Outra economia (2009). Enfim, não temos por objetivo apontar o conjunto das produções teóricas nesse campo educação e economia solidária, mas apenas assinalar alguns trabalhos que são fundamentais.
} 
Solidário (ADS/CUT) em parceria com outras 23 Instituições desse campo, bem como os projetos financiados pelo PRONINC - Programa Nacional de Incubadoras de Cooperativa.

\section{Paul Singer e a educação como estratégia política}

A questão do processo educativo está presente em Singer muito antes da SENAES, pois está indissoluvelmente associada à sua construção da ideia de Socialismo e de sua trajetória em busca da democracia. No livro "Paul Singer. Economia, Democracia, Autogestão" (Santos; Nascimento, 2018), apenas assinalamos alguns elementos educativos presentes na obra de Singer. No presente ensaio, pretendemos mostrar de forma mais articulada seus elementos teóricos para uma pedagogia da autogestão.

Um ponto que não conhecíamos de sua trajetória, é que Singer já se ocupava da questão pedagógica, da formação política, desde sua adolescência, a partir do início de suas experiências no DROR (em hebraico significa 'construtores da liberdade'), um movimento juvenil socialista sionista brasileiro kibutziano do estado de São Paulo. Nos anos 1950, ele tratava da questão pedagógica, pois era o responsável pelo trabalho de formação do movimento. O DROR dedicava atenção especial à formação de seus militantes. Neste período, realizou-se um congresso nacional para traçar as linhas pedagógicas da formação do DROR, e Paul Singer foi o responsável do documento final, que serviu de orientação à formação política do Movimento.

Em sua longa trajetória, Singer passou por várias experiências, de forma direta ou indireta, e de todas foi construindo sua visão de mundo socialista e formulando sua visão do processo educativo. Ao mesmo tempo em que avançava na experiência do DROR, Singer militava no Partido Socialista de São Paulo onde, de forma autodidata, tomou conhecimento das obras de Karl Marx, Rosa Luxemburgo e de outras referências socialistas.

De certa forma, poderíamos dizer que a ideia de Singer sobre socialismo e sobre educação é uma combinação de ideias de Rosa Luxemburgo (sobre a Revolução Russa e as comunidades pré-capitalistas) e as ideias pedagógicas de Paulo Freire (com quem conviveu no Governo municipal do Partido dos 
Trabalhadores, período que a prefeitura de São Paulo tinha como prefeita Luiza Erundina - 1988-1991). A estas fontes teóricas acrescemos as experiências políticas práticas. No campo dos movimentos sociais, destacamos os Kibutz no âmbito do DROR e, a experiência da lugoslávia ${ }^{6}$, Solidarnosc/autogestão na Polônia ${ }^{7}$, o 1968 francês $^{8}$ e nos EUA ${ }^{9}$. No campo do cooperativismo, Singer se referencia da experiência histórica de Rochdale na Inglaterra ${ }^{10}$, a cooperativa Mondragon ${ }^{11}$ no país Basco; No campo acadêmico, as experiência da Unitrabalho ${ }^{12}$ e da Rede Universitária de Incubadoras Tecnológicas de Cooperativas Populares ITCPs ${ }^{13}$ e, por fim, no campo de políticas públicas, o período do governo petista de São Paulo e as experiências da SENAES.

$\mathrm{Na}$ trajetória de Singer, algumas experiências foram decisivas, mas analisando o conjunto da obra, há dois pontos de partida, conforme indicado anteriormente: a obra de Rosa Luxemburgo e a experiência no DROR.

Em 1950, o DROR realizou seu primeiro congresso educacional e um dos resultados foi o documento "Fundamentos de nossa Educação", aprovado com

\footnotetext{
6 Em 1950 o partido comunista iugoslavo (renomeado Liga dos Comunistas da lugoslávia, LCl) legislou (fazendo parte da constituição de 1963) o novo modelo econômico baseado num socialismo autogestionário, no caso, na formalização de conselhos proletários responsáveis pela gestão tanto de unidades produtivas como de territórios.

7 Uma federação sindical polaca fundada em 1980. Tratou-se de um amplo movimento social antiburocrático que utiliza os métodos de resistência civil não-violenta para fazer avançar a causa dos direitos dos trabalhadores e da mudança social.

8 Onda de protestos que teve início com manifestações estudantis para pedir reformas no setor educacional. O movimento cresceu tanto que evoluiu para uma greve de trabalhadores que balançou o governo do então presidente da França, Charles De Gaulle.

${ }^{9}$ A rebelião estudantil de 1968 nos Estados Unidos contestou a estabilidade econômica e social do país.

${ }^{10}$ Criada em 1844 por 28 operários - 27 homens e 1 mulher, em sua maioria tecelões, no bairro de Rochdale-Manchester, na Inglaterra, e reconhecida como a primeira cooperativa moderna, a "Sociedade dos Probos Pioneiros de Rochdale" (Rochdale Quitable Pioneers Society Limited) forneceu ao mundo os princípios morais e de conduta que são considerados, até hoje, a base do cooperativismo autêntico.

11 O Complexo Cooperativas de Mondragon é um exemplo mundialmente famoso por sua capacidade de reunir 120 empresas sob forma de Cooperativas, sendo 87 industriais, 1 de crédito (Caja Laboral), 1 de consumo (Eroski), 4 agrícolas, 13 cooperativas de pesquisa, 6 de serviços em consultoria e 8 cooperativas de educação. São associados das Cooperativas apenas seus trabalhadores que atualmente somam 93 mil pessoas. Na essência todas as cooperativas de Mondragón são Cooperativas de Trabalho que possuem produtos e serviços diferentes entre si.

${ }^{12}$ Rede Interuniversitária de 5 Estudos e Pesquisas sobre o Trabalho (UNITRABALHO) é uma Rede Nacional de Universidades, fundada em 1996, que reúne em torno de 93 instituições de ensino superior, públicas e comunitárias, de todo o Brasil.

${ }^{13}$ A Rede Universitária de Incubadoras Tecnológicas de Cooperativas Populares (Rede de ITCPs) nasceu em 1998 e é formada, atualmente, por 41 incubadoras cujo objetivo é apoiar a formação e consolidação de empreendimentos de economia solidária, bem como prestar assessoria e formação a grupos já consolidados.
} 
entusiasmo, cuja redação final ficou a cargo de Paul Singer (PINSKY, 2000). Dessa ação educativa, Singer recordava:

Eu sei que inspirei para burro o Movimento na parte educacional. Eu me guiava muito pelas minhas leituras pessoais. Havia um traço socialista, necessário, e nesse a gente tinha toda a liberdade, então, a gente avançou muito (PINSKY, 2000, p.146).

Em entrevista de 2008, Singer falou sobre a influência de Rosa Luxemburgo:

É, acho que há um legado luxemburguiano do qual eu não estava consciente antes desse momento. $\mathrm{E}$ o legado me parece ser este: para Rosa Luxemburgo, quem dirige a revolução é o que ela chama de 'as massas'; são os próprios trabalhadores, homens, mulheres, os jovens, enfim. (...) De qualquer forma, na crítica de Rosa à Revolução Russa, essa visão das massas como carregando o ímpeto da mudança é uma coisa que calou fundo em mim. Eu a reencontrei na economia solidaria. (...) em sintonia com esta visão, a economia solidaria foi uma criação das pessoas em situações difíceis, mas recorrendo às forças comunitárias que são socialistas, em última análise...Agora, o que me encanta na economia solidaria é que ela vem de baixo" (SINGER, 2000, p. 24-25).

Na sequência, vamos focalizar alguns elementos de aprendizagem de Singer nestas experimentações de autogestão.

\section{A experiência democrática: experimentações autogestionárias do mundo}

As violências ditadoras que Singer viveu na sua história, com destaque para a experiência da infância que o refugiou no Brasil - o nazismo - e os 21 anos da ditadura militar lhe ensinaram a valorizar a liberdade e a democracia como princípio central de organização da vida. Não por acaso, sua perspectiva de desenvolvimento estava estreitamente relacionada à democracia na economia e a autogestão.

Nesta perspectiva, Singer compreendia que a transformação da realidade social se daria por um processo democrático e autogestionário que corresponderia a uma revolução social, contrapondo à revolução política. A revolução política direciona a energia para a conquista do poder governamental e estatal; a revolução social é um processo lento que duraria muito tempo para superar o capitalismo como sistema econômico, tal como custou para o capitalismo superar as estruturas feudais (Singer, 1998). Assim, a lógica de desenvolvimento que vislumbrava passava por um processo endógeno, de dentro para fora, de baixo para cima, onde as experiências de base e de comunidade teriam um acento absoluto. Para Singer, "esse 
desenvolvimento tem que se dar por um processo de livre aprendizado, em que cada autogestor tenha a possibilidade de abandonar a experiência e se inserir em outro modo de produção" (PINSKY, 2000, p.160).

O Kibutz, que almejava no movimento de sua juventude, foi sua primeira experiência de autogestão de base comunitária. Como já sinalizado, na hora de migrar para Israel e viver em um Kibutz, Singer optou em ficar no Brasil. Mas, em 1985, visitou por 15 dias um Kibutz em Israel e o compara as 'aldeias comunistas" do socialista utópico Robert Owen. Dentre as questões que destacava na experiência era a liberdade do movimento.

A qualquer hora você pode pedir o desligamento do Kibutz, receber uma certa quantidade de dinheiro e tentar sua vida no mundo capitalista. (...) O fato da porta estar sempre aberta dá ao Kibutz uma qualidade essencial. Se quisermos, um dia, chegar ao socialismo, terá de ser por profunda convicção, e essa convicção terá de ser livre, ou não é convicção: é coação (SINGER, 2018, p.161).

Ainda refletindo sobre os feitos das experiências autogestionária, Singer chamava a atenção para vivência da lugoslávia, com um olhar luxemburguiano. Tratou-se de uma experiência longa, que começou em 1950, aproximadamente, e foi até a década de noventa. Segundo Singer, a experiência lugoslava foi prejudicada pelo fato de não haver democracia no país, corroborando com a sua perspectiva de que não é viável tomar o poder primeiro e só depois criar, de cima para baixo, uma economia autogestionária livre (Singer, 2018). Segundo Lowy, esta experiência contribui para a reflexão sobre a revolução social.

Dessa lição aprofundou sua visão da diferença entre 'revolução política' e 'revolução social'. Isto é, na visão luxemburguiana: "A construção de uma nova sociedade é um terreno virgem que põe 'mil problemas" imprevistos; ora, só a experiência permite as correções e a abertura de novas vias. O socialismo é um produto histórico que nasce da própria escola da experiência: o conjunto das massas deve participar desta experiência, senão o socialismo é decretado, doado por uma dezena de intelectuais reunidos em torno de um tapete verde (LOWY, 2018, p. 74-75).

A experiência polaca do Solidarnosc, 1980-1981, também ganhou espaço na reflexão de Singer. Avesso a qualquer forma de violência e opressão para garantia de direitos dos trabalhadores (aliás esta era uma de suas principais criticas à ditatura do proletariado comunista de Marx), Singer percebia no Solidarnosc uma estratégia vinda de baixo pelas massas, mas sem imposição, que num processo 
político organizativo abandonou sua postura de sindicato e exigiu uma "república autogerida" (LOWY, 2018).

Em outro momento, Singer defendeu a ideia de um "Parlamento Econômico", que se assemelha a proposta do Solidarnosc de uma "Câmara de produtores associados, eleita exclusivamente por produtores associados". Destas experiências de lutas pela autogestão, Singer destaca o caráter de experimentação.

\begin{abstract}
A importância dessas experiências é o aprendizado que proporcionam a segmentos da classe trabalhadora de como assumir coletivamente a gestão de empreendimentos produtivos e a operálos, segundo princípios democráticos e igualitários (SINGER, 2000, p. 44).
\end{abstract}

Aqui mais uma vez ressoa a voz de Rosa Luxemburgo quando afirmou no Congresso de Fundação do Partido Comunista de Alemanha (KPD), com base nos princípios da "Liga Spartacus": as massas devem aprender a usar o poder exercendo o poder, não há outro modo, (Lowy, 2018, p.79). Como disse Singer, "para uma ampla faixa da população, construir uma economia solidária depende primordialmente dela mesma, de sua disposição de aprender e experimentar" (SINGER, 2002, p.112).

A partir da reflexão de Singer, destacam-se também as experiências cooperativistas de Rochdale (1844, na Inglaterra) e Mondragon (1956, na Espanha). Essas duas experiências tinham um lugar privilegiado na compreensão de Singer sobre a democratização da economia como estratégia de contraponto ao sistema dominante. Além de expressarem uma dinâmica de escala, ou seja, de avançarem da proposta micro para macro, estas duas experiências traçam uma linha do tempo, uma história sobre a prática continua da autogestão. Singer apontava estas duas experiências como exemplos positivos de cooperativismo, apesar das crises.

Esses exemplos, que se limitam ao pouco que consegui levantar até agora, dão uma ideia de que há uma prática contínua de autogestão desde há pelo menos um século e meio, no mínimo(...). Muitos datam seu início a contar da famosa cooperativa de Rochdale, que é de 1844, mas é perfeitamente possível começar a contar antes, com as cooperativas formadas na Inglaterra por inspiração de Robert Owen, na década de vinte do século passado. (SINGER, 2018, p.157).

Sobre Mondragon, Singer dizia "vejam que há experiência de longo período. Essa de Mondragon tem 42 anos e tem tido muito êxito econômico" (SINGER, 2018, p. 157). 
Singer as conhecia, sobretudo, através da obra "A Acumulação do Capital" de Rosa Luxemburgo (1984). A experiência da SENAES também levou Singer a uma visão aprofundada do papel das comunidades no processo de democratização da economia. Singer ressalta o tema das comunidades e dizia que o fermento da economia solidaria está nas comunidades, nos territórios e que a economia solidaria vem de baixo. Singer estava convencido que no Brasil, foram as forças das circunstâncias que levaram as pessoas se organizarem em iniciativas de economia solidaria. Assim, chamava a atenção para a importância dos sujeitos:

O grande impulso para a economia solidaria vem das comunidades pobres; é lá que está o fermento social que se viabiliza - portanto nos quilombolas, nas comunidades indígenas e, sobretudo, no campesinato e no artesanato. Para essa gente, compartilhar é fazer autogestão e uma certa democracia de base. É uma coisa natural. Eles se inclinam a isso (SINGER, 2008, p.25).

Essa visão sobre as Comunidades se estende ao tema do desenvolvimento solidário, experimentado em programas territoriais enquanto Singer estava à frente da SENAES. "Eu tenho dito várias vezes - nunca escrevi, não tive tempo de escrever- que o campesinato hoje é vanguarda porque é só entre os camponeses que você pode fazer agricultura ecológica" (Singer, 2008, p.28).

\section{A experiência da SENAES e os esforços para legitimar a economia popular solidária como uma estratégia pedagógica ${ }^{14}$}

Na SENAES, Singer extrai elementos fundamentais para reflexão sobre pedagogia da autogestão, inclusive com uma perspectiva gramsciana:

(...) uma grande parte da construção do socialismo tem de ser realizada ainda sob hegemonia capitalista. O conjunto da economia solidária assim constituída deve ser considerado como uma vasta escola de capacitação socialista" (SINGER, 2018, p.159).

E, mais especificamente, dizia:

Para que o modo de produção socialista algum dia se torne hegemônico, a instituição de uma superestrutura política, jurídica e

\footnotetext{
${ }^{14}$ Este não é o espaço para uma avaliação da experiência educativa da SENAES, o que demanda um trabalho coletivo, o qual ainda não foi totalmente feito. Todavia, podemos adiantar afirmando que os diversos limites da política pública de Ecosol nos Governos Lula/Dilma, não permitiram a existência de condições estruturais em que as ideias de Singer no campo educativo pudessem se desenvolver plenamente, tanto no Programa de Agentes de Desenvolvimento Solidário, quanto a estratégia da Rede CFES, deixaram a desejar em seus objetivos principias.
} 
cultural socialista terá de ser precedida da conquista de competência gerencial e domínio da tecnologia por parte de numerosos trabalhadores socialistas (SINGER, 2018, p.159).

Isto é, parte significativa da construção do socialismo tem de ser realizada ainda sob a hegemonia capitalista, construindo uma contra hegemonia numa perspectiva socialista autogestionária. Desta forma, podemos sintetizar a política da SENAES, no campo educacional, pode ser expressa em dois princípios singerianos, a ECOSOL como ato pedagógico e também como uma escola de capacitação socialista. Destes princípios, temos dois campos de projetos de política pública, ou seja, dois caminhos de experimentação autogestionária: projetos territoriais de Agentes de Desenvolvimento Solidário e Projeto de Rede-CFES de Educadores,

\section{Projetos territoriais de Agentes de Desenvolvimento Solidário (ADS)}

A estratégia dos Agentes de Desenvolvimento Solidário implica em compreender o desenvolvimento como totalidade, significa envolver a comunidade. Para Singer (2018) este processo de desenvolvimento requeria um relacionamento simbiótico entre comunidade os agentes de desenvolvimento da SENAES, profissionais destacados para articular as diferentes políticas no território. Estes representavam bancos públicos, serviços públicos (como Sebrae ou Sescoop), agências de fomento da economia solidaria, ligadas a Igreja, sindicatos ou universidades ou então movimentos sociais. No decorrer de uma articulação no território, criam-se as condições de organização democrática do mesmo. Instituições surgem por meio de espaços dos quais a comunidade se organiza para promover o seu desenvolvimento: assembleias de cidadãos, comissões para diferentes tarefas, empresas individuais, familiares, cooperativas e associações de diferentes naturezas, comitês mistos público-privados (SINGER, 2018, p. 210 -211).

Por esta estratégia passava a necessidade de a comunidade desenvolver a consciência de que o desenvolvimento é possível pelo esforço conjunto da comunidade, amparado por credito assistido e acompanhamento sistemático (incubação).

Quanto ao aspecto pedagógico, a comunidade deve desencadear um processo educativo, de educação política, econômica e financeira de todos os 
sujeitos. Trata-se de capacitação adquirida no enfrentamento dos problemas reais, a medida que os mesmos vão se apresentando (SINGER, 2018, p. 211).

O relacionamento entre a comunidade e os agentes deve se tornar crescentemente igualitário, mediante a continua troca de saberes. Nesta troca, os membros da comunidade recebem ensinamentos e os oferecem aos agentes, num processo de educação política mútua. (...) O ideal é que a preparação se faça em equipe...Também aqui a pedagogia da capacitação será possivelmente a mais adequada: treinamento teórico entremeado por idas à comunidade, onde a luta com os problemas reais levantará novos temas a serem destrinchados depois, no estudo teórico. (SINGER, 2018, p. 211).

Singer destacava a importância de esta proposta garantir a diversidade das experiências. "Os métodos de promoção não podem ter a pretensão de oferecer um caminho único ou a melhor prática, pois, cada comunidade é única em suas potencialidades" (Singer, 2018, p.211). Continua:

O pequeno tamanho da comunidade pobre e o seu relativo isolamento fragilizam suas possibilidades de se desenvolver por meio próprio (com apoio público). Um Centro nacional de preparação de agentes de desenvolvimento poderia promover entrosamento das comunidades...UMA FEDERAÇÃO DE COMUNIDADES com a mesma especialização, seja ela agricultura, artesanato, turismo ou o que for, configura o que hoje se conhece como ARRANJO PRODUTIVO LOCAL (...). O centro nacional poderia colocar as comunidades, com possibilidades de se federar, em contato e os agentes de desenvolvimento as assistiriam na construção de APLs". Para Singer, a Internet facilitaria a articulação de comunidades com proximidade geográfica(...) "Comunidades com especializações complementares -tecidos, confecções, produtora de rações e criadoras de animais etc.- terem boas razões para se federar...O Centro nacional de preparação poderia criar espaço de negociação (SINGER, 2018, p. 212).

Na SENAES houve duas experiências nesse sentido: o Programa de Desenvolvimento Local, com base em agentes, foi uma experiência nesse sentido, e depois o Projeto "Brasil Local".

\section{Projeto de Rede-CFES de Educadores.}

Os CFES foram implantados, a partir de 2009, em cinco grandes regiões do país (Norte, Nordeste, Sudeste, Centro-Oeste e Sul em 2010) e um Centro de âmbito nacional (Brasília). Sua finalidade era de articulação do todo, como um projeto de política pública da SENAES. Pretendia realizar a formação de educadores / formadores, a sistematização das experiências educativas e a disseminação de 
metodologias de educação popular, a experimentação da autogestão pedagógica e organização de uma rede nacional de educadores. Ou seja, as atividades desenvolvidas pelos CFESs deveriam contribuir na preparação de educadores capazes de atuar em empreendimentos solidários e assim fortalecer o movimento como um todo, para assegurar formação, capacitação e assistência técnica adequada às características organizacionais dos empreendimentos e práticas de economia solidária.

$\mathrm{Na}$ perspectiva estratégica, a formação realizada no CFES corresponde a uma "construção social", na medida em que seus princípios, métodos e aprendizados sugerem um novo desenvolvimento através de trabalhos autogestionários, da busca pela sustentabilidade, vivência da democracia no local de trabalho e participação cidadã fora do empreendimento.

Nesse sentido, a educação em economia solidária centra-se tanto no conhecimento ético-político quanto técnico-produtivo. Este segundo aspecto é reconhecido, em geral, como assessoria ou formação técnica voltada para o aperfeiçoamento do processo de organização legal, produção de bens ou prestação de serviços. Entre os conteúdos sugeridos cada CFES buscou repensá-los considerando as diversidades culturais e os contextos locais e regionais das práticas, as vivencias e experiências de cada grupo social no qual a economia solidária local se insere.

\section{A ECOSOL como um ato pedagógico: algumas considerações finais}

Mas, sem dúvidas, a obra principal de Singer sobre o tema da pedagogia da autogestão ou da economia solidaria, é o ensaio "A economia solidaria como ato pedagógico", que fez para uma coletânea do INEP (2005): "Economia solidaria e EJA", organizada por Sonia M. P. Kruppa, então secretaria-adjunta da SENAES. Tratou-se das primeiras formulações para política de educação da ECOSOL.

Vimos que, em 2004, Singer elaborou o ensaio sobre desenvolvimento solidário em que propôs a fundação de um centro nacional de capacitação. $O$ termo referência para formação em economia solidaria, definido no campo do Plano Nacional de Qualificação (PNQ), data deste período. A primeira oficina nacional de formação da SENAES/FBES foi realizada em 2005. 
No conjunto de sua obra, Singer pensa a ECOSOL "como modo de produção ideado para superar o capitalismo" (Singer, 2004, p.13). Na sequência desta reflexão, Singer faz a distinção entre "empresa solidaria e empresa capitalista e indica os desafios pedagógicos" como questão central para consolidação de outras formas de produzir e viver.

Fica claro que a prática da economia solidaria exige que as pessoas que foram formadas no capitalismo sejam reeducadas (...). Essa reeducação tem de ser coletiva(...). Essa visão não pode ser formulada e transmitida em termos teóricos, apenas em linhas gerais e abstratas. o verdadeiro aprendizado dá-se com a prática, pois, o comportamento econômico solidário só existe quando é recíproco. Trata-se de grande variedade de práticas de ajuda mútua e de tomadas coletivas de decisão. (SINGER, 2004, p.16).

Singer gostava de afirmar que, na ECOSOL, os princípios são o horizonte, e a pratica o critério de verdade.

O sentido da experimentação, e o par razão/emoção são ressaltados por Singer: A pedagogia da economia solidaria requer a criação de situações em que a reciprocidade surge espontaneamente, como o fazem os jogos cooperativos....A economia solidaria é produzida tanto por convicção intelectual como por afeto pelo próximo, com o qual se coopera. (SINGER, 2004, p.16)

Nesta perspectiva, Singer apresenta um contraponto daqueles que formam seu imaginário de vida e de sociedade a partir capitalismo, em situação de competição, aos que se formam no meio da economia solidaria, que vivem situações definidas por comportamentos recíprocos de ajuda mútua. No entanto, a economia solidária torna-se uma alternativa de inserção dos trabalhadores no mercado de trabalho frente ao desemprego e à exclusão social, ou seja, trata-se de uma adesão por força das circunstâncias. A adesão ao processo da ECOSOL como estratégia política só acontece mais tarde, a partir da vivência dos valores e princípios da autogestão, até então os trabalhadores mal sabiam do que tratava a ECOSOL (Santos, 2010). Afirma a autogestão como processo pedagógico para os trabalhadores:.

na realidade, a educação que a luta de classes proporciona aos operários está embebida em valores solidários e igualitários, que estão na base do socialismo, enquanto projeto e utopia" (...) por isso, os trabalhadores, assim como os pequenos produtores de mercadorias e os pobres em geral, inclinam-se espontaneamente para ECOSOL.... a partir dessa inclinação espontânea, a tarefa pedagógica impõe-se. (...) e que: por terem sido subalternos e alienados da gestão do empreendimento, que agora lhes incumbe não só operar, mas dirigir, os trabalhadores não estão preparados 
para a tarefa. eles têm que ser ensinados e eles sabem disso (SINGER, 2004, p.17).

Singer aborda um dos dilemas da política de educação da ECOSOL, a divisão entre formação política e formação técnica. Assim, inicia pela divisão de campos na educação. O ensino da autogestão dividido em duas partes: uma, a cargo de teóricos, investigadores ou veteranos da ECOSOL; outra, a cargo de especialistas, investigadores ou veteranos da economia capitalista. Essa divisão acabaria por levar os empreendimentos solidários a adotarem procedimentos incompatíveis com seus princípios. Exemplifica essa divisão com o caso da contabilidade e finanças, em que se separa o ensino das finanças do ensino da autogestão (SINGER, 2004, p 18).

Assim, Singer vai definindo o que pode ser elemento para uma pedagogia da autogestão:

em outras palavras, o ensino da autogestão não tem por que ser dividido em uma parte própria, interna aos empreendimentos, e outra externa aos mesmos, porque o meio ambiente em que atuam os empreendimentos solidários pode ser composto inteiramente por outros empreendimentos solidarios (SINGER, 2004, p 19).

Tendo em vista o amplo campo da ECOSOL no Brasil (empresas recuperadas, cooperativas em assentamentos da reforma agraria, cooperativas de recicladores, de agricultores familiares e muitos outros), Singer compreendia que a formação na ECOSOL passava pelo um princípio metodológico da educação popular e afirmava que a efetividade desse ensino decorre da estreita conexão entre seus fundamentos teóricos e sua aplicação pratica (Singer, 2004). Dizia:

devemos a Paulo Freire esta formulação lapidar, ninguém ensina nada a ninguém; aprendemos juntos. Isso se aplica inteiramente à ECOSOL, enquanto ato pedagógico. Nessa interação, produz-se um auto aprendizado mutuo. Somos todos autodidatas, pois não há aprendizado verdadeiro em que a curiosidade do aprendiz não tenha papel crucial. (SINGER, 2004, p 19).

Para concluir, voltamos ao eixo central de sua ideia:

A ECOSOL é um ato pedagógico em si mesmo... por isso, a solidariedade é ensinada aos fracos e subalternos pela vida e pelas empreitadas em que se engajam... é a vida que ensina aos mais fracos, aos socialmente e economicamente debilitados, o valor, na verdade, a imprescindibilidade da solidariedade..."Contudo, "A ECOSOL é um passo decisivo 'para além' desse aprendizado pela vivencia, pois ela propõe a solidariedade não só como imposição da necessidade, mas como opção por outro modo de produção. (SINGER, 2004, p.20). 


\section{Referências}

ADAMS, T. SANTOS, A. M. Economia Solidária: um espaço peculiar de educação popular. In: STREC, D. ESTEBAN, M (orgs). Educação Popular. Lugar de construção social coletiva. São Paulo: Vozes, 2013.

CUNHA, G. SANTOS, A, M. Economia solidária e pesquisa em ciências sociais: Desafios epistemológicos e metodológicos. In: HESPANHA, P. SANTOS, A. M (orgs.), Economia Solidária: Questões Teóricas e Epistemológicas. Coimbra: Almedina, 2010.

FÓRUM BRASILEIRO DE ECONOMIA SOLIDÁRIA. Histórico - Do Fórum Social Mundial ao Fórum Brasileiro de Economia Solidária. Disponível em http://www.fbes.org.br, 2005.

A experiência de gestão e organização do Movimento de Economia Solidária no Brasil. Brasília: FBES, Secretaria Executiva, 2006.

LOWY, M. Rosa Luxembourg, I"etincelle incendiaire. essais. le temps des Cerises. Paris, 2018.

LUXEMBURGO, R.. A acumulação do Capital. São Paulo: Abril Cultural, 1984.

MANTEGA, G; REGO, J. M. Conversas com economistas brasileiros. São Paulo: Editora 34, v. 2, 1999.

NOVAES, H. Mundo do trabalho associado e embriões de educação para além do Capital. Marilia: Editora Lutas anticapital, 2018.

NASCIMENTO, C. Rosa Luxemburgo e Solidarnosc. Rio de Janeiro: Loyola, 1986.

Autogestão na Pedagogia. Ensaios. IEEP. SP, 2011.

Experimentação autogestionária: autogestão de pedagogia e

pedagogia da autogestão. In: Trabalho, educação e reprodução social. Bauru: Práxis, 2013.

A educação em economia solidária (pedagogia e autogestão). Texto para debate em Oficina do Projeto Redes de Cooperação solidária. ADS-CUT/SENAES. Disponível em: www.claudioautogestao.com.br, 2014.

Referenciais metodológicos de formação e assessoria técnica em economia solidária. Brasília: REDE CFES, 2016.

PINSKY, C. Pássaros da Liberdade: jovens, judeus e revolucionários no Brasil. São Paulo: Contexto/Fapesp, 2000.

SANTOS, A.M. NASCIMENTO, C. Paul Singer: Democracia, Economia e Autogestão. Marilia: Lutas Anticapital, 2018.

O movimento de economia solidária no Brasil e os dilemas da organização popular. Rio de Janeiro: Tese de doutorado UERJ, 2010.

SECRETARIA NACIONAL DE ECONOMIA SOLIDÁRIA/MTE. Plano de Ação 2004.

Brasília: MTE, SENAES, 2004a. 
Termo de Referência do Sistema Nacional de Informações em Economia Solidária. Brasília: MTE, SENAES, 2004b.

Atlas da Economia Solidária no Brasil 2005. Brasília: MTE, SENAES, 2006a.

. Anais da I Conferência Nacional de Economia Solidária. Brasília: MTE-MDAMDS, 2006b.

Documento final da Conferência Temática de economia solidaria e autogestão. Brasília: MTE, SENAES, 2014.

Projeto de promoção de desenvolvimento local e economia solidaria. Brasília: MTE/SENAES, 2006c.

SINGER, P. O que é o Socialismo hoje? Petrópolis: Vozes, 1980.

. Uma utopia militante. Repensando o socialismo. Petrópolis: Vozes, 1998.

. Oito hipóteses sobre a implantação do socialismo via autogestão. Revista

Temporales. FFLCH/UFSP, 1999.

. Introdução à Economia Solidária. São Paulo: Perseu Abramo, 2002.

Economia Solidária. In: CATTANI, Antonio David (Org.). A outra economia. Porto Alegre: Veraz, 2003.

A economia solidaria como ato pedagógico. In: KRUPPA, Sonia (org). Economia Solidaria e educação de jovens e adultos. INEP, Brasília, 2004.

Entrevista com Paul Singer. In: LOUREIRO, I (org.). Socialismo ou Barbarie.

Rosa Luxemburgo no Brasil. Instituto Rosa-Luxemburg-Stifung. São Paulo, 2008.

É possível levar o desenvolvimento a comunidades pobres. In: Ensaios sobre

Economia Solidária. Coimbra: ALMEDINA, 2018.

SINGER, P; MACHADO, J. Economia Socialista. São Paulo: Perseu Abramo, 2000.

; SCHIOCHET, V. La construcción de La economia solidária como alternativa ao capitalismo. In: CORAGGIO, J.Luiz (org.). Economia social y solidaria em movimento. Buenos Ayres: Clacso/IAEN, 2016.

TIRIBA, L. FISCHER M. C. Saberes do Trabalho Associado. In Cattani, A.; Laville, J.L.; Gaiger, L. I.; Hespanha, P. (orgs.), Dicionário Internacional da Outra Economia. Coimbra: Almedina, 2009.

; PICANÇO, I. Trabalho e educação: arquitetos, abelhas e outros tecelões da economia popular solidaria". Aparecida/São Paulo: Ideias e Letra, 2004. 